\title{
HaVANA: A CIDADE COMO CATÁSTROFE em ANTONIO José Ponte
}

Rodrigo Lopes de Barros

As novas ruínas não adquiriram ainda a gasta pátina da idade, a verdadeira ferrugem da Guerra dos Barões, não posta contudo sobre sua hera; tampouco equiparam-se com o bestiário apropriado de lagartos, morcegos, serpentes, corujas, sapos rajados ou pequenas raposas que, como é tão frequentemente observado pelos exploradores de ruínas, mantém uma alta festividade nos recintos das velhas ruínas [...]. Mas as novas ruínas são por algum tempo inóspitas e nuas, sem vegetação ou criaturas; enegrecidas e em pedaços, elas cheiram a fogo e mortalidade.

Rose Macaulay, Pleasure of Ruins

O antropólogo Fernando Ortiz, autor de um dos mais importantes livros com fim de forjar a cubanidade e a identidade nacional da ilha caribenha, intitulado Contrapunteo cubano, certa vez sentenciou naquele texto a relação entre território e tempo, que havia tido lugar após a chegada de Colombo e antes da revolução socialista.

Toda escalada cultural, que a Europa experimentou em mais de quatro milênios, em Cuba aconteceu em menos de quatro séculos. O que lá foi subida por rampas e degraus, aqui foi progresso a saltos e sobressaltos. Em um dia passaram-se em Cuba várias eras; diríamos milhares de "anos-culturais" se fosse admissível tal métrica para a cronologia dos povos.

Mas, agora, ao contrário deste tempo acelerado visto por Ortiz, Cuba parece viver o mesmo dia há mais de meio século, num tempo que se suspendeu. ${ }^{1}$ Havana se tornou um grande museu a céu aberto, com seus carros cinquentenários, seus prédios antigos e assim por diante. De acordo com Giorgio Agamben, poderíamos dizer que o caso de Havana faz parte de um evento mais geral. A modernidade enfrenta um fenômeno chamado museificação.

- (ORTIZ, Fernando. Contrapunteo cubano del tabaco y el azúcar: advertencia de sus contrastes agrarios, económicos, históricos y sociales, su etnografía y su transculturación. Havana: Jesus Montero Editor, 1940: 139.)

\footnotetext{
${ }^{1}$ Sobre a aceleração do tempo na modernidade, ver: KOSELLECK, Reinhart. Futuro passado: contribuição à semântica dos tempos históricos. Rio de Janeiro: PUC Rio Editora, 2006.
} 
- (AGAMBEN, Giorgio. Profanações. São Paulo: Boitempo, 2007: 73 .)

• (LITVAK, Lily. "El Siglo de los museos". Conferência proferida no I Seminario Internacional "Memoria y Patrimonio", Granada, 12 de novembro de 2009.)

(PONTE, Antonio José. Un arte de hacer ruinas. México D. F.: Fondo de Cultura Económica, 2005: 61-62.)
A museificação do mundo é atualmente um dado de fato. Uma após outra, progressivamente, as potências espirituais que definiam a vida dos homens - a arte, a religião, a filosofia, a ideia de natureza, até mesmo a política - retiraram-se, uma a uma, docilmente, para o Museu. Museu não designa, nesse caso, um lugar ou espaço físico determinado, mas a dimensão separada para a qual se transfere o que há um tempo era percebido como verdadeiro e decisivo, e agora já não é. O Museu pode coincidir, nesse sentido, com uma cidade inteira (Évora, Veneza, declaradas por isso mesmo patrimônio da humanidade), com uma região (declarada parque ou oásis natural), e até mesmo com um grupo de indivíduos (enquanto representa uma forma de vida que desapareceu). De forma mais geral, tudo hoje pode tornar-se Museu, na medida em que esse termo indica simplesmente a exposição de uma impossibilidade de usar, de habitar, de fazer experiência.*

O Museu, que foi pensando como um espaço utópico no século XIX e teve sua arquitetura "concebida a partir de textos utópicos inspirados na noção de conhecimento universal" - como podemos aprender de um ensaio de Lily Litvak -, " pode também adquirir um significado catastrófico. Esta é uma das leituras que o escritor cubano Antonio José Ponte faz de Havana e sua museificação. Para Ponte, em seu conto Un arte de hacer ruinas, caminhar pelos exteriores daquela cidade é como fazer uma viagem ou, até mesmo, uma viagem no tempo. A história é sobre a crise de se escrever uma tese de doutorado sobre urbanismo, e seu orientador, que é responsável por guiar o estudante, mostra-lhe que há uma estreita conexão entre espaço e tempo, isto é, entre geografia e história. Daí então, ele essencialmente incita seu discípulo a tornar-se um viajante do tempo para que possa escrever sobre a arquitetura havaneira. "Quando se é criança, a geografia nos apaixona muito mais que a história. Outros países importam muito mais que outras épocas. Será que talvez não temos que começar nossas viagens no tempo. [...] O tempo, como devem ter te ensinado, é um espaço a mais. Agora, cabe a você explorá-lo.”* Ele precisa explorar este museu chamado Havana, o tempo da cidade, como se este estivesse indissociavelmente fundido com o espaço. Este museu não é, no entanto, uma entidade completa, concreta, mas encontra-se mais próximo do vazio, do deserto. A preservação dos prédios de Havana também significa transformá-los, como fim último, em construções para exibição sem possibilidade de usar, de habitar ou de experienciá-los. De acordo com Ponte, em seu livro La fiesta vigilada e no ensaio La Habana: ciudad y archivo (escrito a pedido do 
Cuban Research Institute, Universidade da Florida), a museificação de Havana se tornou também um projeto oficial, ao invés de ser simplesmente um resultado gratuito da revolução. Assim, museificação na política atual de Cuba adquire o significado de desertificação. O próprio projeto de restauração incorpora uma prática demográfica que contribui para o esvaziamento gradual do casco histórico. "La ciudad museo dedicada al turismo internacional necesita estos trabajos de desertificación.”* E sobre os possíveis desdobramentos deste processo, ele também escreve: "a cidade antiga, seus charmosos edifícios protegidos poderiam se converter no futuro em uma zona tão apetecível como o centro histórico de outras capitais do mundo."

O estado de paralisação temporal em que se encontra Havana pode dar origem não apenas a um museu, mas também a uma paisagem de ruínas. Ponte escreve: "durante quase cinquenta anos, Havana se manteve paralisada, e a essa paralisação, a esse colapso trazido por ela, teremos que dar a cara. [...] E é tamanha a magnitude do desastre, que se poderá falar de uma [nova] fundação da cidade." Para Ponte, que se define como ruinólogo, Havana se faz principalmente de catástrofes e escombros. Neste sentido, a museificação da cidade antiga coexiste com as ruínas das partes restantes. Ele escreve que "não se poderia aspirar a uma capital arquelogizada, uma cidade convertida em museu", pois se isto acontecesse Havana se tornaria uma "nova Pompéia, a Pompéia enterrada pelo vulcão Revolução". " O tempo é também o autor das ruínas. Ruínas e museu, este aparente paroxismo é o que constitui Havana.

A variedade geológica que distingue a arquitetura havaneira, rica em estratos de distintas eras, deve-se ao estatismo imobiliário imposto pela administração revolucionária. A capital cubana goza, graças a isto, de um invejável caráter museístico. Ainda que também de um desmoronamento adjacente ao irresolúvel: Havana é um museu em ruínas.

Este desmoronamento é também uma prática de se criar espaços vazios, desertificação: "fabricar um vazio onde falta uma construção é o recurso que se busca em uma cidade que perdeu o habito de edificar".*

Além do caso cubano, no entanto, museificação e arruinamento podem também trabalhar juntos em muitos aspectos teóricos, como quando o crítico de arte britânico Kenneth Clark criou o War Artists Advisory Committee, o qual enviava pintores às cida-
"(PONTE, Antonio José. "La Habana: ciudad y archivo". Relatório comissionado ao Cuban Research Institute, Universidade da Florida. Disponível em: cubainfo. fiu.edu.)

- (lbidem: 9.)

(Ibidem: 15.)

-(Ibidem: 11.)

- (PONTE, Antonio José. La Fiesta Vigilada. México D. F.: Fondo de Cultura Económica, 2007: 178.)

(Ibidem: 149.) 
"(lbidem.)

'(VIRILIO, Paul. Guerra e Cinema. São Paulo: Editora Página Aberta, 1993.)

(Ver: AGAMBEN, Giorgio. Estado de Exceção. São Paulo: Boitempo, 2003.)

• (BENJAMIN, Walter. "Das Passagen-Werk". In: Gesammelte Schriften, vol. V-1. Frankfurt: Suhrkamp Verlag, 1982: 59.)

•(BUCK-MORSS, Susan. The dialectics of seeing: Walter Benjamin and the Arcades project. Cambridge: MIT, 1991: 159.) des do Reino Unido, que haviam sido incendiadas pelos bombardeios alemães, para que retratassem as ruínas. Nesta perspectiva, Ponte volta a Cuba, para dizer que "Havana é o cenário de uma guerra que nunca aconteceu”. 'Ou seja, após a crise dos mísseis em 1962, Havana foi transformada em uma cidade bombardeada por um bombardeio que nunca aconteceu. "Estas ruas destruídas pelos bombardeios do tempo são o perfeito cenário para o discurso de praça sitiada. Havana é um local na extensão deste anseio [...] pelo ataque militar que John F. Kennedy não se realizou, e que nem foi realizado até hoje por nenhum de seus sucessores na presidência”. Lá, em talvez mais que nenhum outro lugar, o poder bélico de destruição do inimigo é dado como pura aparência, em imagens, como bem define a guerra Paul Virilio. "Havana então é abandonada em ruínas a fim de tornar-se uma cidade bombardeada e impedir o processo de esquecimento do estado permanente de guerra contra os Estados Unidos que tem seu aspecto mais tangível no embargo econômico e na escassez por ele proporcionada. Nesta perspectiva, para usar outra definição desenvolvida por Agamben, ousaríamos até mesmo dizer que Cuba vive um estado de exceção que já dura cinquenta anos.

De acordo com os estudos parisienses de Walter Benjamin, um dos mais importantes ruinólogos, as ruínas são resíduos de um mundo dos sonhos. "O desenvolvimento das forças de produção pulverizou os símbolos de desejo do século passado, mesmo antes que os monumentos que os representavam houvessem desmoronado." Segundo Buck-Morss, ao analisar o trabalho de Benjamin, vemos que "estas estruturas decadentes não mais têm influência sobre a imaginação coletiva, por isto é possível reconhecê-las como imagens de sonhos ilusórios que sempre foram". * No caso de Havana, porém, este mundo dos sonhos é uma junção da utopia revolucionária de 1959 com o poder conservador que a sucedeu e que não apenas se alia com a utopia de massas soviética, mas também anseia pelo bombardeio estadunidense (para se tornar o palco central da guerra), e não simplesmente o mundo capitalista das mercadorias - embora essas matrizes utópicas estejam inseridas no mesmo projeto de modernidade, como nos mostra a filósofa estadunidense em outro estudo, agora comparativo entre estes dois mundos, oportunamente intitulado Dreamworld and Catastrophe: "é crucial reconhecer que o fim da era soviética não foi espacialmente limitado ao território da União Soviética. O experimento 
bolchevique [...] estava vitalmente anexado ao projeto modernizador ocidental, do qual não pode ser extraído sem fazer com que o próprio projeto caia em pedaços - incluindo seu culto ao progresso histórico"* Há um lugar no tempo, porém, em que Paris e Havana, Benjamin e a revolução cubana, podem ser finamente lidos juntos por meio de um fragmento do passado. Em outras palavras: o historiador Rafael Rojas, em seu texto Walter Benjamin no llegó a la Habana, relata que o crítico alemão considerou seriamente se exilar no Caribe caso conseguisse realizar sua fuga da Europa cada vez mais tomada pelos nazistas. Nas cartas trocadas com Adorno, eles cogitaram a possibilidade de Benjamin assumir um posto de professor visitante na Universidade de Havana. A impossibilidade de conseguir um visto e a iminência de ser capturado pelos nazistas, no entanto, levaram-no a cometer suicídio na fronteira entre a França e a Espanha, antes de ter a oportunidade de tocar o solo cubano onde ele poderia expandir seus estudos sobre a arquitetura, um espaço diferente onde talvez refletisse novamente sobre o flâneur ao vagar pelas esquinas daquela cidade, como ele também havia tentado em sua visita a Moscou. Para Rojas, entretanto, Benjamin não chegou a Havana por duas vezes, fisicamente e como um intelectual lido pelos cubanos, uma vez que suas teses não puderam ser estudadas em Cuba devido ao domínio da ideologia marxista-leninista, que se endureceu no mesmo ritmo em que o reconhecimento póstumo de Benjamin, como um dos mais radicais pensadores da modernidade, espalhava-se pelo ocidente. ${ }^{*}$ Talvez agora, mesmo que com todos os contra-ataques que isto tenha causado, poderíamos dizer que Benjamin adentrou os becos de Havana por meio de Ponte. Para este, Havana é uma espécie de Paris pré-moderna, e a política das ruínas levada a cabo pela administração cubana pode apenas dar origem a uma total demolição e reconstrução da cidade como aconteceu em Paris sob a tutela Haussmann que, de acordo com Benjamin, deu a si próprio o título de "artista da demolição". Haussmann, em alguns aspectos, antecipa a lógica dos bombardeios. Estas táticas consistem em alcançar a aniquilação total, como Sebald nos conta em seu estudo Luftkrieg und Literatur, ao citar alguns dos generais aliados que comandaram, na segunda guerra mundial, as incursões aéreas sobre as cidades alemãs que reduziram a cinzas aqueles locais:

Sr. Arthur Harris, um homem que havia acendido ao topo do Comando de Bombardeios, [...] apreciava a destruição pela destruição,
- (BUCK-MORSS, Susan. Dreamworld and Catastrophe: the passing of mass utopia in East and West. Cambridge: MIT, 2002: 68.)

- (ROJAS, Rafael. "Walter Benjamin no llegó a la Habana". In: FONT, Mauricio A. (org.). Changing Cuba/ Changing World. Nova York: Bildner Center for Western Hemisphere Studies, 2008.) 
(SEBALD, Winfried Georg. Luftkrieg und Literatur: mit einem Essay zu Alfred Andersch. Munique: Carl Hanser, 1999: 28.)

- (BUCK-MORSS, Susan. "The City as Dreamworld and Catastrophe". In: October, Vol. 73, Verão, 1995: 25.)

- (SEBALD, Winfried Georg. Luftkrieg und Literatur, op. cit.: 48.)

• (PONTE, Antonio José. Un arte de hacer ruinas. op. cit.: 73.)

- (VIDLER, Anthony. Warped Space. Cambridge: MIT, 2001: 76-77.) e estava assim em perfeita simpatia com o mais profundo princípio de toda guerra, que tem por objetivo uma aniquilação tão indiscriminada do inimigo com suas habitaçôes, sua história e seu ambiente natural quanto seja possível de se realizar.

Justamente é esta aniquilação, proporcionada pelo emprego em massa dos avióes militares, que faz o imaginário urbano se distanciar cada vez mais de um mundo dos sonhos:

a imagem coletiva da cidade como um espaço utópico foi abalada fundamentalmente na Segunda Guerra Mundial pelos ataques aéreos catastróficos [...]. Por certo, cidades ao redor do mundo continuaram a $[\ldots]$ prometer $[. .$.$] sonhos de consumo. Mas uma contra-$ -tendência é cada vez mais aparente: os sonhos estão divorciando-se do espaço da cidade. ${ }^{*}$

Nesta perspectiva, em uma cidade que foi transformada catastroficamente em ruínas por meio de bombardeios, algumas vezes é somente possível viver no subterrâneo, nos abrigos antiaéreos. Sebald narra, por exemplo, a história de famílias que viveram por anos no subsolo das cidades alemãs bombardeadas. "Em Hamburgo, diz Dagerman, ele conversou com um tal de Herr Schumann, um caixa de banco já então no seu terceiro ano vivendo no subsolo. As caras brancas daquelas pessoas, escreve Dagerman, eram como caras de peixe vindo a superfície para roubar um pouco de ar". Se formos de volta ao conto escrito por Ponte, Un arte de hacer ruinas, nós descobriremos que Havana, a cidade bombardeada, esconde uma cidade subterrânea abaixo de seus prédios em ruínas. A cidade chama-se Tuguria, e a entrada que leva ao seu túnel principal é um abrigo antiaéreo. Tuguria é "a cidade submersa, onde tudo se conserva como na memória”. Sim, pois como nos fala Anthony Vidler, memória e espaço constituem o centro nevrálgico da arquitetura, o espaço arquitetônico é uma ficção para algo mais, para algo potencialmente esquecido, e neste sentido Benjamin conceberia o subterrâneo como um equivalente ao inconsciente da cidade: "em sua imaginação, Paris foi transformada à semelhança de uma escavação antiga, com suas ruínas, seus lugares sagrados e até mesmo sua entradas ao submundo". Tuguria, esta cidade subterrânea, é composta pelos prédios desmoronados de Havana e que lá ressurgem. Segundo a história, os habitantes da cidade secreta seriam os tugures que são responsáveis por derrubar os prédios acima do solo. "Teria que reconhecer que ali existia uma cidade muito parecida com a de cima. Tão parecida que teria sido planejava por aque- 
les que proporcionavam os desmoronamentos". Este tipo de demolição, esta prática, levaria o nome de tugurização.

Os mais velhos edifícios da cidade chamam a atenção dos tugures. Não passava muito tempo até que um primeiro tugur fosse viver no edifício espreitado. Este primeiro conseguia trazer outros e pouco a pouco o enchia com sua gente. [...] Buscavam o desmoronamento por todos os meios. E não para morrer, pois um legítimo tugur propiciava a queda de um edifício sem que lhe pousasse em cima nem a poeira de um tijolo.*

O tugur é um tipo de nômade e o nomadismo é difícil em uma ilha tão pequena. A ilha é aquilo que na verdade torna o nomadismo impossível. Ao caminhar, sempre se depara com o oceano, então para os tugures, que não podem deixam a ilha, a única alternativa é cavar. Ponte escreve em seu conto: "quando você não encontra terra nova, quando está cercado, pode lhe sobrar ainda um recurso: fazer reluzir aquela que está debaixo do construído. Escavar, caminhar na vertical. Procurar a conexão da ilha com o continente, a chave do horizonte". A cidade, consequentemente, cresce para baixo. Esta verticalização do nomadismo tugur tem uma vasta similaridade com a cosmogonia fundacional da modernidade que, de acordo com Rosalind Willians, é também vertical.

O cosmos da tecnologia moderna, tanto quanto aquele da mitologia antiga, tem uma estrutura vertical. Da mesma maneira que ele atinge as alturas nas formas de arranha-céus, pontes ferroviárias, plataformas de petróleo e mísseis, ele também submerge ao fundo da terra nas fundaçōes de edifícios, túneis ferroviários, poços de petróleo e silos de mísseis. A decida abaixo da superfície terrestre foi em parte uma busca pela verdade científica; foi também uma busca por poder tecnológico. Os triunfos da moderna vida urbana e industrial emergem das conexōes enterradas abaixo da superfície da terra. As estruturas se apoiam em infraestruturas escondidas.

Não é a toa que, por exemplo, o escritor de ficção-científica H. G. Wells, que viveu no auge da construção subterrânea industrial, retratou o futuro como um civilização submersa em seu livro Time Machine* (primeiramente publicado em 1895) - texto que desencadeia um topos retomado daí em diante pela ficção científica, como em Memórias encontradas numa banheira de Stanisław Lem, no qual a tensão entre memória e subterrâneo mais uma vez se estabelece na história sobre uma sociedade militarizada e submersa onde um agente secreto deve espionar o que nem ele mesmo tem conhecimento. A história se refere a um manuscrito encontrado
- (PONTE, Antonio José. Un arte de hacer ruinas. op. cit.: 72-73.)

"(Ibidem: 66.)

-(WILLIANS, Rosalind. Notes on the Underground. Cambridge: MIT, 2008: 50.)

- (WELLS, H. G. The time machine: an invention. Londres: W. Heinemann, 1895.) 
• (LEM, Stanisław. Memoirs found in a Bathtub. Nova Iorque: The Seabuty Press, 1973: 1.) num tempo longínquo, mas elaborado no período neogeneo (termo pelo qual a civilização do futuro refere-se ao que chamamos de idade antiga até a contemporânea) pouco antes do Grande Colapso: "aquele evento catastrófico que em questão de semanas demoliu as realizaçōes culturais de séculos", e depois do qual, "aquelas culturas arcaicas deixaram para trás monumentos em osso, pedra, ardósia e bronze". ${ }^{*}$ E assim continua o texto que apresenta as Notas do Neogeneo

Muito do Neogeno, tememos, permanecerá para sempre eclipsado na memória, pois até mesmo os métodos de cronotração falharam em propiciar os detalhes mais fundamentais da vida social daquela época. [...] A evolução das crenças antigas sofreram uma curiosa bifurcação. No primeiro período, o Arqueocredónico, várias religiōes foram fundadas sobre o reconhecimento de um princípio não material e supranatural, causativo com respeito a tudo em existência. O Arqueocredónico deixou monumentos permanentes - as pirâmides do Baixo Neogeno, as escavações do Mesogeno (as catedrais góticas de Lafranss). No segundo período, o Neocredónico, a fé assumiu um diferente aspecto. $\mathrm{O}$ princípio metafísico de algum modo fundiu-se com o materialista, terreno. O culto a divindade Kap-Eh-Taahl (ou, nos palimpsestos cremônicos, Kapp-Taah) tornou-se um dos cultos dominantes da época. [...] Até o final - isto é, a formação da Federação da Terra - o centro de mais fanática devoção ao Kap-Eh-Taahl era Ammer-Ka, uma terra governada por uma série de dinastia de Prez-tendz. Estes não eram altos sacerdotes do capital do Kap-Eh-Taahl no sentido estrito da palavra. Foi durante a XIX Dinastia que os Prez-Tendz (ou Prexy-dents, na nomenclatura da escola historiográfica de Thyrric) construíram o Pentagon. [...] No fechamento do Neogeno [...] o culto do Kap-Eh-Taahl, espelhado em ritos corporacionais complexos e rituais institucionais intrincados, começou no curso do tempo a perder um território sobre o outro para os seguidores do gerenciamento sociostático secular. [...] [O arqueólogo] Wid-Wiss defendeu sua hipótese, reivindicando que quando a população da Ammer-Ka passou para o lado dos "heréticos" e se uniu a Federação, os sacerdotes do Último Pentagon ordenaram que ele fosse completamente fechado ao mundo exterior. Assim os Moloch subterrâneos se isolaram do resto da humanidade e suportaram o Caótico sem o menor conhecimento do que estava acontecendo do lado de fora sobre a superfície da terra. [...] Nossos Histognostores responderam a estes argumentos com um silêncio inexorável. Mas Wid-Wiss não desistiu. Por vinte e sete anos, com apenas um punhado de colegas leais para ajudá-lo, ele esquadrinhou as Rocket Mountains de ponta a ponta. Quando quase todos o haviam esquecido, sua teimosia foi drasticamente vindicada. Em 28 de maio de 3146, o chefe da equipe arqueológica, tendo retirado várias toneladas de cascalho da base do Pico Harr-Vurd, parou diante de 
um escudo convexo, inteligentemente camuflado, excelentemente preservado: era a entrada para o Último Pentagon. ${ }^{2}$

A cidade subterrânea de Tuguria, abaixo de Havana, cuja entrada principal é também a boca de um túnel, feito a construção submersa de Lem (o "último" e mais seguro refúgio do que haveria restado da contemporaneidade e, portanto, núcleo fundador e alicerce da superfície que nos é aparente), talvez seja a maneira pela qual Cuba igualmente insere-se nesta tradição industrial. Ou melhor, é maneira com que aquela nação pode participar da modernidade, pois, como Willians argumenta, utilizando-se das ideias de Lewis Mumford, "a cidade moderna envolve a coordenação da cidade da suprassuperfície com a cidade da sub-superfície", da mesma maneira que a Paris de Haussmann estudada por Benjamin foi feita tanto pela demolição quanto pela escavação subterrânea. Haussmann empreendeu uma regularização dos subterrâneos de Paris. "Quando Haussmann e Belgrand começaram, Paris tinha menos de 160 quilômetros de esgotos. Em 1870, no final do Segundo Império, a cidade tinha 560 quilômetros, ou aproximadamente quatro vezes o total de 1851. Assim, como [Victor] Hugo nota com orgulho, o sistema de esgoto parisiense havia se expandido em dez vezes entre os anos de 1800 e 1870". Num gesto simétrico ao de Richard Wright (altamente influenciado por Victor Hugo), que insere a negritude estadunidense (então vista como signo do arcaico) na cidade moderna por meio dos esgotos e do subsolo em The man who lived underground, ${ }^{3}$ a participação de Cuba na modernidade é também alcançada ao expandir seu subterrâneo, mas isto é feito não apenas através da cidade submersa de Tuguria, ou das construções de esgotos, ou na tentativa de um metrô, mas também por meio da espionagem.

Em seu ensaio "La Habana: ciudad y archivo", Ponte escreve sobre esta outra cidade subterrânea: "pode-se falar também de uma cidade secreta, submergida, na qual foram parar as mais impensáveis conversas, as cartas que não chegaram ou não saíram até seu

\footnotetext{
${ }^{2}$ Ibidem: 6-11. Faz-se bem notar que esta ligação entre capitalismo e religião mostrada por Stanisław Lem está muito alinhada ao que Walter Benjamin expôs sobre o assunto em um de seu texto: "Kapitalismus als Religion". In: Gesammelte Schriften, vol. VI. Frankfurt: Suhrkamp Verlag, 1982: 100-103.)

${ }^{3}$ Ver: WRIGHT, Richard. "The man who lived underground". In: Accent: a quarterly of new literature. Spring, 1942, Urbana: 170-176. Uma versão ampliada foi posteriormente incorporada na coletânea: Eight Men. Cleveland: World Pub. Co., 1961.
}

-(WILLIANS, Rosalind. Notes on the Underground. op. cit.: 52.)

(Ibidem: 71-72.) 
"(PONTE, Antonio José. "La Habana: ciudad y archivo". op. cit.: 8.)

(DERRIDA, Jacques. Mal de arquivo: uma impressão freudiana. Rio de Janeiro: Relume Dumará, 2000: 21.)

• (RONELL, Avital. Campo de Provas: sobre Nietzsche e o test-drive. Desterro [Florianópolis]: Editora Cultura e Barbárie, 2010: 37.)

- (HEIDEGGER, Martin. "Was heißt Denken?" In: Gesamtausgabe - Abteilung I: Veröffentlichte Schriften, 1910-76. Vol. 08. Frankfurt: Vittorio Klostermann, 2002: 31.)

" (NODARI, Alexandre. "Teses sobre a política". In: Sopro, $\mathrm{n}^{\circ} 23$, Desterro, março de 2010: 4.)

- (AGAMBEN, Giorgio. "Metropoli". Texto apresentado no seminário Metropoli/Moltitudine, Università IUAV di Venezia, 11 de novembro de 2006.) destino [...], [o universo telefônico paralelo, a escuta]. Refiro-me à cidade [...] composta de quilômetros e quilômetros de arquivos secretos". Mas este arquivo é impelido não pela força acumulativa da memória, mas pela corrosão, esta cidade arquivo não é uma Tuguria, no sentido de uma cidade memorial, mas seu oposto, ou talvez seu duplo (já que o arquivo é ao mesmo tempo destruidor e conservador), sua outra face, um arquivo que não produz fala, mas tão-somente a violência inigualável do silêncio. Se fossemos às teorias de Derrida, diríamos que estas cartas que não chegam, e até todo o complexo da espionagem em si, formam parte desta força anarquívica, arquiviolítica, pois "ela trabalha, mas, uma vez que trabalha sempre em silêncio, não deixa nunca nenhum arquivo que lhe seja próprio. Ela devora seu arquivo, [...] sempre foi, por vocação, silenciosa, destruidora de arquivo". "Nisto, Ponte é preciso, esta cidade subterrânea da espionagem expande-se juntamente com o deserto na superfície, os espaços de desertificação têm como aspecto último a criação de um calar-se intransponível, de uma falta de questionamento, de uma ausência de teste, isto é, de uma "presunção não testada por excelência, sustentada por pseudo-preceitos" e que não coloca em cheque a ideologia, para usarmos os termos de Avital Ronell ao comentar sobre o experimento em Nietzsche. ${ }^{*}$ E como Heidegger bem notou, Nietzsche gritava: "o deserto cresce" [die Wïste wächst], não apenas uma terra devastada se propaga, mas toda uma intelectualidade estéril. ${ }^{*}$ A desertificação, neste sentido, pode inclusive significar censura, pois, sendo fruto desta interceptação do pensamento por meio da espionagem, "esvazia as formas da imaginação coletiva, substituindo-as por uma pura forma em que garante, antes de tudo, o seu controle, inscrevendo a sua marca, a marca da mediação" - na conceptualização de Alexandre Nodari. Em suma, a cidade submersa da espionagem é o efeito colateral do deserto (de um governo que atravessa a própria natureza do governado, de um poder não transcendente mas imanente), ${ }^{*}$ deste espaço devastado que cresce e que assume a paisagem da superfície e propaga o silêncio: eis um par indissociável, deserto e silêncio, aos olhos daqueles que puderam caminhar pelo local da morte para receber no fim, junto com Paul Bowles, o batismo da solidão.

Logo que se chega ao Saara, pela primeira ou décima vez, nota-se a quietude. Um silêncio incrível e absoluto prevalece fora das cidades; e dentro delas, até mesmo em lugares cheios como os mer- 
cados, há uma qualidade soturna no ar, como se aquele mutismo, ressentindo-se da intromissão do som, minimizasse e o dispersasse imediatamente. Então, tem-se o céu, comparado com o qual todos os outros céus são esforços tímidos. Sólido e luminoso, ele é sempre o ponto focal da paisagem. No pôr-do-sol, a sombra arqueada e precisa da terra acende rapidamente do horizonte, seccionando-o em duas partes, uma de luz, outra de escuridão. Quando toda luz se esvai, e o espaço encontra-se carregado de estrelas, o céu ainda se faz de um intenso e ardente azul, mais escuro diretamente acima e empalidecendo ao encontro da terra. Assim, a noite nunca se torna de fato negra. Você deixa o portão do forte ou a cidade para trás, passa pelos camelos deitados do lado de fora, sobe as dunas, ou segue pelo terreno plano, e para de pé, sozinho. Em pouco tempo, ou vai tremer e correr de volta para dentro dos muros, ou continuará lá, de pé, e deixará algo muito peculiar acontecer com você, algo que todos que lá vivem sofreram e que os franceses chamam le baptême de la solitude. É uma sensação única, e não tem nada a ver com a solidão, pois a solidão pressupõe memória. Aqui, nesta paisagem inteiramente mineral, iluminada por estrelas feito chamas, até a memória desaparece. Nada resta a não ser sua própria respiração e o som do seu coração batendo.

Onde até a memória desaparece, só resta aquilo que Agamben chamou de vida nua, isto é, "a vida matável e insacrificável". * O ser humano, quando se depara com o deserto que domina cada vez mais as esferas do vivido, torna-se reduzido a esta vida biológica, ao som do ar percorrendo as traqueias e ao da marcha de um coração a bater.

\section{Rodrigo Lopes de Barros}

Doutorando em Literatura Hispânica pela Universidade do Texas, Austin. Mestre em Teoria Literária pela Universidade Federal de Santa Catarina (UFSC), onde foi bolsista do CNPq. Membro do Núcleo de Estudos Benjaminianos, NEBEN.

\section{Resumo}

Ortiz viu a aceleração do tempo em Cuba. A museificação (Agamben) tornou-se, porém, a ordem do dia na Havana pós-revolucionária. Para Ponte, caminhar pelas ruas de Havana é fazer uma viagem no tempo. Ela não é apenas um museu, mas um museu em ruínas. Havana é uma cidade bombardeada por um bombardeio que nunca ocorreu. Assim, a vida é levada ao subterrâneo. Tuguria, a cidade submersa, está, contudo, em total sincronia com o deserto que toma a paisagem.
- (BOWLES, Paul. "Baptism of Solitude". In: Collected Stories and Later Writings. Nova York: The Library of America, 2002: 813.)

- (AGAMBEN, Giorgio. Homo sacer: o poder soberano e a vida nua. Belo Horizonte: Editora UFMG, 2007: 16.)

Palavras-chave: museificação; ruínas; subterrâneo 
Key words: museification; ruins; underground.

Palabras clave: museificación; ruinas; subterráneo.

\section{Abstract}

Ortiz saw the acceleration of time in Cuba. However, the museification (Agamben) has become the agenda of post-revolutionary Havana. For Ponte, to walk through the streets of Havana is like to undertake a time travel. The city is not only a museum but also a muse$\mathrm{um}$ in ruins. Havana is a bombarded city by a bombing that never took place. Thus, life goes underground. Tuguria, the submerged city, is however fully synchronized to the wasteland that grows on the surface.

\section{Resumen}

Ortiz vio la aceleración del tiempo en Cuba. Sin embargo, la museificación (Agamben) se ha convertido en el orden del día en La Habana posrevolucionaria. Según Ponte, caminar por las calles de La Habana es como hacer un viaje en el tiempo. La cuidad no es solamente un museo, sino también un museo en ruinas. La Habana es una cuidad bombardeada por un bombardeo que jamás ocurrió. Así, la vida pasa a ser subterránea. Tuguria, la ciudad sumergida, está, con todo, en total sincronía con el desierto que toma el paisaje. 